\title{
JOSHUA GREENE E MARC HAUSER NAS FRONTEIRAS DA FILOSOFIA: A MORAL DAS MORAIS EVOLUCIONISTAS
}

\author{
JOSHUA GREENE AND MARC HAUSER ON THE FRONTIERS OF \\ PHILOSOPHY: THE MORALITY OF THE EVOLUTIONIST MORALS.
}

\author{
TELMA DE SOUZA BIRCHAL \\ (UFMG / Brasil)
}

\begin{abstract}
Resumo
Este artigo trata das implicações filosóficas de teorias científicas em moral. Na primeira parte apresenta duas teorias intuicionistas sobre a natureza dos julgamentos morais (a de Joshua Greene e a de Marc Hauser) e na segunda explicita as consequências filosóficas que cada um dos cientistas extrai de sua teoria. A conclusão faz uma avaliação dessas consequências e uma reflexão sobre possíveis implicações do naturalismo em ética.

Palavras-chave: Naturalimo, evolucionismo, julgamentos morais.
\end{abstract}

\begin{abstract}
This paper explores the philosophical implications of some scientific theories in morals. The first part presents two intuitionist theories about the nature of moral judgments (Joshua Greene's and Marc Hauser's theories); the second part points out the philosophical consequences that each one of these scientists extracts from their theories. The conclusion makes an evaluation of these consequences and a reflection about naturalism in ethics.
\end{abstract}

Key-words: Naturalism, evolutionism, moral judgements

Inquiry into our moral nature will no longer be the property of the humanities and social sciences, but a shared journey with the natural sciences (Marc Hauser). Naturalistic fallacy cannot be used to ward off ethical debates the way that a crucifix is used to ward off vampires (D. S. Wilson et allii). La vraie morale se moque de la morale (Pascal).

\section{Introdução}

Pesquisas desenvolvidas pela biologia e psicologia em torno da moral - ou seja, o conhecimento, digamos assim, descritivo da moral - estão relacionadas a concepções filosóficas mais gerais, tanto de caráter metaético quanto de caráter prescritivo. $\mathrm{O}$ assunto é amplo e intenso o debate sobre ele na literatura, como prova o recente livro de K. A. Appiah, Experiments in Ethics, que reúne vários exemplos de pesquisa empírica em moral e apresenta uma bem fundada discussão sobre a repercussão filosófica dessas pesquisas. ${ }^{1} \mathrm{O}$ presente trabalho tem um pequeno escopo, concentrandose em duas teorias intuicionistas recentes e nas consequências filosóficas que os próprios cientistas 
pretendem extrair delas. $^{2}$

\section{I - DUAS TEORIAS SOBRE OS JULGAMENTOS MORAIS}

Biólogos e psicólogos pesquisam, em seus laboratórios, os processos de produção dos julgamentos morais, com recursos variados, que vão desde a aplicação de questionários e testes, passam pela observação de pessoas expostas a situações conflitivas ou a dilemas e chegam ao estudo do cérebro por ressonância magnética. Um cenário um tanto esquisito para nós, filósofos, que julgamos que fazemos melhor lendo Aristóteles ou Kant.

Atualmente, uma conclusão parece consolidar-se na literatura científica a partir das pesquisas empíricas: a de que a maior parte de nossos julgamentos morais se dá de forma automática e imediata. São as chamadas "intuições morais". Uma definição bastante satisfatória de intuição é apresentada por Haidt: ela é um julgamento, solução ou conclusão que aparece repentinamente a alguém, sem derivar de um processo consciente. "A intuição (...) é uma espécie de cognição, mas não é um raciocínio". De forma que raciocínio e intuição são duas formas diferentes de cognição, sendo o raciocínio, ao contrário da intuição, consciente e constituído de etapas. As emoções, por sua vez, se diferenciam das intuições por não serem cognições" (HAIDT, 2001, 814-818). O intuicionismo em moral, portanto, defende que, na maior parte das vezes, julgamos e agimos moralmente sem consciência das razões dos julgamentos e comportamentos. Mesmo discordando nos detalhes ao acentuar diferentes aspectos deste fenômeno, muitos cientistas colocam-se em oposição às concepções dominantes em filosofia desde os gregos, mas também à psicologia de Piaget e de Kohlberg que afirma que a moral é, fundamentalmente, uma questão de razões e de consciência, de escolhas ponderadas e iluminadas por motivos. ${ }^{3}$

Uma das provas do caráter intuitivo dos julgamentos morais estaria no fato de que é comum as pessoas terem fortes convicções, mas se encontrarem numa verdadeira situação de "mudez moral" (moral dumbfounding) ao tentar justificá-las. Elas nem sempre encontram razões para suas intuições ou, no melhor dos casos, as razões surgem depois de feito o julgamento (justificativas ad-hoc).

Pesquisadores utilizam o dilema do trem desgovernado (trolley problem) para investigar as intuições morais. ${ }^{4}$

\section{O dilema do trem desgovernado}

Cenário 1 - Um trem desgovernado, cujo maquinista desmaiou, vai matar cinco pessoas que se encontram sobre os trilhos. Um observador pode, acionando uma alavanca, desviá-lo para 
outro trilho sobre o qual se encontra uma pessoa, que será ela a morrer. O observador deve acionar a alavanca?

Cenário 2 - Um trem desgovernado, cujo maquinista desmaiou, vai matar cinco pessoas que se encontram sobre os trilhos. Um observador que se encontra sobre uma ponte acima dos trilhos percebe que, se empurrar um homem que pesa $120 \mathrm{~kg}$ e que se encontra a seu lado, o corpo do homem será capaz de, caindo sobre os trilhos, fazer parar o trem e salvar as cinco pessoas. $\mathrm{O}$ observador deve empurrar o homem?

Em geral, as pessoas SIM no primeiro cenário e NÃO no segundo.

Chamadas a dar as razões destes julgamentos - afinal, os dois casos são idênticos em termos de cálculo; em ambos uma pessoa morre e cinco são salvas pelas ações dos observadores -, as pessoas geralmente se encontram em uma situação de "mudez moral". Estão convencidas de sua escolha, mas não sabem explicar por quê. Ou então suas explicações não são coerentes. A força da convicção é desproporcional à força das razões.

Os cientistas, por sua vez, elaboram teorias que pretendem explicar o fato de as duas situações serem julgadas diferentemente pelas pessoas. A matéria, no entanto, é polêmica, e as explicações divergem. Alguns, como Joshua Greene e Jonathan Haidt, acentuam o papel do componente afetivo e emocional nas intuições morais. Outros, como Marc Hauser, pensam as intuições como informadas por princípios, ou seja, carregadas de um componente cognitivo inconsciente.

\section{Greene e o papel das emoções}

Joshua Greene, professor de Psicologia em Harvard, oferece a seguinte explicação para a diferença de julgamento entre os dois casos acima: "Sustentamos a opinião de que, de um ponto de vista psicológico, a diferença fundamental entre o dilema do trem e o da ponte é que o último engaja a emoção das pessoas de uma maneira que o primeiro não engaja” $(2001,2106)$.

Enquanto no primeiro cenário a situação é impessoal, envolvendo o ato indireto de acionar uma alavanca, no segundo cenário ela é pessoal, envolvendo o ato direto de empurrar uma pessoa. Estudos de ressonância do cérebro mostram que, em casos como o primeiro, o julgamento é feito por áreas mais ligadas ao raciocínio. Já em casos como o segundo são ativadas áreas ligadas à emoção e à cognição social. Greene conclui: "Talvez este par de intuições morais não tenha nada a ver com 'alguma boa razão', mas com a maneira como nosso cérebro está construído (...) as pessoas em apuros que estão próximas apertam nossos botões emocionais, enquanto as que estão longe da vista estão longe do coração" $(2003,848){ }^{5}$

Assim, não há propriamente uma boa razão para o julgamento, mas, sim, causas que são, 
imediatamente, a grande participação das emoções e, mediatamente, a origem evolutiva dos sentimentos altruístas. Nossos instintos altruístas evoluíram em um ambiente em que as necessidades de ajuda eram a pessoas muito próximas e geralmente envolvendo grande sacrifício pessoal. Em suma, construímos nossas regras morais a partir parâmetros de comportamento que se originam em nossa vida pré-histórica e que, talvez, não se justifiquem em um novo contexto ou diante de exigências racionais.

Serão, então, as regras e princípios que regem a moral realmente morais? Essa é a questão filosófica essencial que pode ser formulada a partir do naturalismo de Greene e que retomaremos em nossa conclusão.

\section{Hauser e os princípios universais}

Marc Hauser, professor de Biologia e Psicologia evolucionistas em Havard e autor de Moral Minds, também parte da centralidade das intuições em moral, mas tem outra visão da natureza delas. Sua tese fundamental é a de que as emoções não são o principal fator na moral; pelo contrário, uma série de observações e experimentos em torno das intuições morais o leva a postular a existência de princípios cognitivos inatos do certo e do errado. Em termos teóricos, Hauser se fundamenta principalmente em Chomsky, mas também em Rawls.

Para compreender essa idéia, tomemos a interpretação que Hauser oferece do trolley problem. Ele afirma que há, a rigor, uma diferença estrutural entre os dois casos: no primeiro cenário, o mal (matar uma pessoa) seria uma consequência prevista do bem que se intenciona, no segundo caso ele seria um meio intencionado para o bem. Encontramos aqui o "princípio do duplo efeito", que possibilita distinguir entre os dois casos, de forma a permitir o mal no primeiro caso, mas não no segundo. Nosso cérebro, armado com este princípio, inconscientemente capta a diferença, o que explica a discrepância entre os julgamentos nas duas situações - ou seja, o que está em jogo não é apenas ou primariamente uma questão emocional, o processo tem também um caráter racional, embora inconsciente.

A pertinência do princípio do duplo efeito é uma questão polêmica, mas ele é apenas um dos argumentos, além da análise de uma profusão de dados da psicologia, antropologia e biologia, para fundamentar a proposta de Hauser de que todos os humanos têm uma faculdade moral - "uma capacidade que permite a cada indivíduo, inconscientemente e automaticamente, avaliar uma ilimitada variedade de ações em termos de princípios que ditam o que é permitido, obrigatório ou proibido" $(2006,36)$. Nossos julgamentos morais não são a expressão direta de emoções, eles são mediados por um conjunto de princípios de raciocínio moral inconsciente que "dispara" nossas emoções morais. No caso do dilema do trem, o sujeito vê a diferença entre os dois casos, o que 
origina diferentes emoções $(223){ }^{6}$

Com a idéia de uma gramática moral universal (GMU), Hauser propõe que a moral seja compreendida em analogia com a teoria de Chomsky, que afirma que os seres humanos têm uma capacidade inata para o desenvolvimento da linguagem, sendo o perfil específico de cada língua particular dado pela cultura. Não obstante as diferenças entre as diversas línguas, há alguns princípios gerais compartilhados por todas elas; analogamente, no mundo moral podemos encontrar alguns princípios universais - como a reciprocidade em justiça e a regra de ouro (não fazer ao outro o que não queremos que nos seja feito) - aos quais a cultura dará a expressão ou forma final. ${ }^{7}$ Ainda, o "órgão moral" remete a muitas capacidades cognitivas humanas como, por exemplo, o senso de cálculo (importante para o desenvolvimento das noções ligadas à justiça), a capacidade de distinguir entre um objeto animado e um inanimado (importante para a atribuição ao outro da capacidade de sofrer) ou entre um ato intencional e um não intencional (importante para o desenvolvimento da noção de responsabilidade). A complexidade do órgão moral é apresentada por Hauser e, embora os princípios sejam refratados de formas diferentes em culturas diferentes, há um solo comum, que é exatamente o conjunto de capacidades do ser humano, que ele chama de "blocos construtores" do senso moral. Enfim, a sociedade faz a mediação entre biologia e a norma; ela não inventa tudo. A faculdade moral do ser humano é fruto da evolução, como parte do nosso "equipamento standard" - já está lá, sem necessidade de aprendizagem (2006, 171).

\section{II - IMPLICAÇÕES FILOSÓFICAS}

Coloca-se, agora, a questão das implicações filosóficas dessas teorias. Registre-se, em primeiro lugar, uma declaração explícita de acordo dos autores acima citados com a chamada "lei de Hume": ambos iniciam seus textos dizendo que não se pode deduzir o "dever" do "ser" - ou seja, o fato de um comportamento ser natural não o tornaria, sem mais, moral (GREENE, 2003, 847 e HAUSER, 2006, 3). De forma que os autores são claramente naturalistas quando se trata de descrever a gênese da moralidade; já quando se trata da justificação da moral a questão se torna mais complexa e mediações têm que ser feitas entre natureza e ética.

Como nos lembra Greene, a ciência tem implicações éticas na medida em que pode mostrar o que se passa "por trás da cena" da moralidade - aumentando assim nosso conhecimento dos processos psicológicos envolvidos na moral. De forma que a ciência teria o que dizer em algumas questões de metaética ou da natureza da ética. Menos evidente é a relação entre as descrições da ciência e as prescrições da moral; no entanto, na medida em que o conhecimento ligado à moralidade é um modo do "conhecimento de si”, ele tem implicações éticas substantivas. Como o próprio Hauser reconhece, uma das diferenças entre o funcionamento da linguagem e o da moral é que, enquanto o conhecimento dos princípios linguísticos não altera o comportamento dos falantes, o 
conhecimento dos princípios ou da natureza da ética pode alterar o comportamento dos agentes morais (158-159).

Exporemos a seguir como os aspectos metaéticos e normativos se desenvolvem e se relacionam nos casos dos dois intuicionismos analisados.

\section{Greene}

\subsection{Crítica ao realismo moral}

Para Greene, a psicologia e as neurociências podem ajudar a arbitrar no debate metaético entre o realismo (ou objetivismo) e o subjetivismo moral. Ele parte do fato de que, na vida cotidiana, a maior parte das pessoas é "realista moral", pois pensa que seus julgamentos são verdades morais independentes da mente. Ao proferirem um julgamento moral, como "mentir é errado", elas têm a convicção de estar falando de algo objetivo, verdadeiro, e não apenas expressando uma opinião ou experiência subjetiva. Ora, segundo o psicólogo, como os julgamentos morais são em geral intuitivos e emocionais, não se tem consciência do processo de sua elaboração - o que explica o fato de eles nos parecem dados e objetivos. Uma perspectiva semelhante encontra-se em Richard Joyce, que defende em The Myth of Morality que o senso de dever é algo que está no nosso cérebro porque herdado evolutivamente e nisso se assenta a impressão que temos de sua objetividade.

Temos então, aqui, um caso em que a ciência explica a gênese de uma teoria filosófica, radicando-a em instintos naturais - o que mostraria, ao mesmo tempo, a insuficiência da teoria realista (GREENE, 2003, 849). De tudo isso o autor tira, como consequência, que uma postura coerente com os dados das ciências seria um subjetivismo ou relativismo moral, pois temos que a moral resulta tanto da configuração de nossos cérebros quanto das experiências culturais e existenciais, não se tratando, portanto, de algo objetivo e transcendente.

Cabe observar aqui que as versões do "realismo moral" que são alvo do ataque de Greene e de Joyce não são adversários fortes. Segundo Greene, o realismo postularia a existência de um "mundo" ou uma "realidade" exterior na qual os julgamentos morais encontrariam um referente. Melhor dizendo, para atribuir realidade ou objetividade à moral, Greene aparentemente exige uma espécie de fonte empírica do conhecimento moral. ${ }^{8}$ Ora, o realismo assim concebido não é um opositor muito difícil de ser vencido - o difícil é encontrá-lo entre os filósofos. Que a moral não seja objetiva, quer dizer, exterior ao ser humano, mas diga respeito a ele e à sua mente é algo que seria afirmado pela grande maioria dos pensadores - nesse sentido a moral será sempre subjetiva ou relativa ao ser humano, ao sujeito humano. No entanto, torná-la humana não implica necessariamente em torná-la relativa e, menos ainda, irreal. 


\subsection{Do fato ao valor}

Retomando Greene, o subjetivismo e o relativismo seriam não apenas consistentes com os dados da ciência, mas recomendáveis do ponto de vista ético. A proposição de que as convicções morais originam-se de uma história evolutiva, cultural e pessoal reforçaria uma postura relativista, que é mais apta a construir um mundo pacificado que as teorias adversárias - Greene assim reafirma a clássica articulação entre relativismo e tolerância.

No entanto, a relação entre ciência da moral e moral filosófica é bem mais complexa, o que se deixa ver quando os mesmos dados da psicologia evolutiva são interpretados em outra direção, alimentando outra metaética, como na teoria apresentada por Hauser.

\section{Hauser}

\subsection{Universalismo}

Na perspectiva de Hauser, como vimos, a biologia aponta para o um universalismo moderado e a natureza é vista não apenas como a origem, mas como a fonte legítima da experiência moral. Um dos pontos importantes de sua argumentação são experimentos que mostram que a capacidade de distinguir entre convenções sociais e normas morais parece ser universalmente compartilhada. Em testes, crianças muito pequenas afirmam que a professora pode autorizar os alunos a virem sem uniforme, ou a comerem seu lanche com as mãos, mas não pode autorizar que um aluno puxe o cabelo do outro. O que indica que as normas morais não podem ser remetidas e explicadas completamente pelas convenções da sociedade, mas que, se é o caso de se fazer uma "genealogia da moral", essa deve ser feita levando em conta também a biologia. "Uma figura de autoridade pode suspender as regras sociais, mas nem mesmo Deus pode suspender uma regra moral.” A articulação entre moral e natureza é explícita: "Pode-se supor que a mente humana tenha certas capacidades que nos permitam - mas não a chipanzés, golfinhos ou papagaios - ver algumas distinções morais e apreciar seu significado para nossas vidas e para a vida dos outros. (...) Se este diagnóstico é apropriado, então algo em nosso DNA permite que exista esta diferença psicológica. E algo no nosso DNA também permite que adquiramos a assinatura única de nossa cultura local” (297-298).

\subsection{Do fato ao valor}

Ao pensar, por sua vez, a passagem do descritivo ao prescritivo, da herança escrita em nossos genes ao valor desta herança, Hauser é cauteloso, mas recomenda que se leve em conta as intuições morais imediatas da maioria das pessoas - de modo a que crenças religiosas, leis e costumes possam ser avaliados a partir delas. Ou seja, políticos e religiosos não deveriam tentar impingir 
valores ou comportamentos que contrariem princípios ou intuições universais identificados. No caso de Therri Schiavo, por exemplo, as autoridades deveriam levar em conta o fato de que uma grande maioria (entre 60 e 70\% das pessoas que responderam à pesquisa de opinião sobre o assunto) pronunciou-se a favor da eutanásia (423). O autor aposta que o universalismo dos princípios pode ser uma espécie de solo comum para o lançamento de um debate multicultural. ${ }^{9}$ A sugestão de que o conhecimento dos princípios descritivos ("ciência da moralidade") pode ajudar no nosso entendimento dos princípios prescritivos é duramente criticada por Rorty, que acentua a importância da cultura e da utopia para a ética. ${ }^{10}$

Numa direção diferente da seguida até agora, Hauser também afirma que a posição normativa mais compatível com a idéia da refração pela cultura de princípios universais é o pluralismo - pois a adesão a um sistema único seria opressiva. Como bem observou Steve Clarke, o livro não oferece critérios para se avaliar a diversidade dos valores ou uma boa resposta diante do relativismo. ${ }^{11}$

De forma que tanto relativistas quanto não relativistas ficam descontentes com a teoria de Hauser, e sem dúvida o seu pretendido universalismo não vai muito além da afirmação de uma espécie de capacidade humana a priori de habitar uma realidade moral, cujo conteúdo será finalmente dado pela cultura. Parece-me que, quaisquer que sejam suas pretensões, ao não oferecer uma clara regra prescritiva, o livro acaba por não ultrapassar os limites do discurso científico sobre a moral - o que é mais uma virtude do que um defeito.

\section{Conclusões}

A suspeita em relação à moral é a consequência mais comum das teses evolucionistas. $\mathrm{Na}$ verdade, como observa Appiah, tanto evolucionistas como não evolucionistas acreditam que a autoridade dos julgamentos morais seria solapada pela explicação evolucionista de sua origem (2008,185-187). Em evolucionistas como Michel Ruse e de Richard Joyce, por exemplo, a moralidade é levada a um certo descrédito ao se revelarem suas origens "humanas, demasiado humanas", ou antes, demasiado naturais. A moralidade seria, então, algo em que acreditamos por força de nossa constituição, não por seu valor intrínseco. Da mesma forma, o naturalismo de Greene sugere que sob o nome "moral" encontram-se comportamentos e princípios meramente adaptativos e que, portanto, não são essencialmente morais. Ora, mesmo concedendo que Greene consiga, em casos concretos, demonstrar que muitas de nossas intuições morais não se justificam de um ponto de vista racional, a afirmação de que a moral natural não é suficientemente ou essencialmente moral leva a um paradoxo. O discurso da suspeita ocupa o lugar a partir do qual uma "verdadeira moral zomba da moral", para retomar o pensamento de Pascal, pois a denúncia da moral natural e evolutiva como insuficiente, irracional ou ilusória é, por sua vez, feita de uma perspectiva em princípio mais moral (autêntica ou confiável) que aquela para a qual a evolução nos dispôs. Assim, Greene torna-se um 
contra-exemplo de sua própria teoria, mostrando que a descrição científica da moralidade não esgota a moralidade. A moral ultrapassa sua descrição.

Já Hauser apresenta uma visão da moral que, sendo naturalista, não implica uma suspeita sobre a sua realidade ou significado, ou mesmo sobre sua verdade. Na GMU a moralidade não é uma espécie de epifenômeno ou algo que simplesmente encobre um comportamento adaptativo; ao contrário, ela existe como uma verdadeira moral dada a estrutura compartilhada por todos os seres humanos e que apela a conteúdos racionais e afetivos. E, se há uma experiência humana da moral, não é preciso ir além dela para afirmar sua realidade - ou antes, o fato de esta experiência ser natural não retira, em princípio, seu significado moral. Pelo contrário, são os princípios naturais e inatos que nos capacitariam a construir uma realidade moral. Aqui subjetivismo e objetivismo se encontram.

Creio ser essa perspectiva o que torna o livro de Hauser filosoficamente interessante. A origem natural ou evolutiva, em si mesma, não implica num solapamento da moral, pelo contrário, o fato de a moral encontrar suas raízes na natureza até reforça seu caráter de objetividade. De fato, não se justifica recusar o caráter moral a algo simplesmente porque sua origem é natural - ao se evitar a todo custo a falácia naturalista, acaba-se cometendo a falácia genética. ${ }^{12}$ Se o que motiva os sentimentos de solidariedade ou a exigência de justiça são disposições naturais eles não são, por isso, menos morais. A não ser que, de saída, só se aceite uma origem exterior ou sagrada para os valores, ou que, por definição, como quer Kant, nossas inclinações não tenham nada a ver com o bem e com o mal.

No entanto, concedendo que de direito, nada impede que a moral seja natural, resta saber se Hauser consegue demonstrá-lo de fato. O principal problema do naturalismo de Hauser é que os inúmeros dados empíricos que ele mobiliza e interpreta nem sempre se articulam ou sustentam sua tese da existência de um "órgão moral" universal fundado na biologia. Muitos dos exemplos de capacidades universais presentes no livro dizem respeito a aspectos não morais (cognitivos) do ser humano. A aproximação com a linguagem é problemática, pois não temos divergências nem conflito na comunidade dos falantes como as temos na comunidade moral. ${ }^{13}$ A idéia de que toda a humanidade compartilha de princípios gerais que se refratam em culturas particulares não se aplica com facilidade. Por exemplo, se todas as culturas aceitam o princípio de que, em algumas situações, o assassinato é permitido ou pelo menos julgado com menos severidade (como nos casos de legítima defesa ou de crimes passionais), a recomendação, presente em culturas particulares, que se mate a pedradas uma mulher acusada de adultério é suficiente para demonstrar que a universalidade do princípio é impotente para ajudar na resolução de conflito dos valores. Nesse caso, como em muitos outros, a interpretação dada pela cultura é tão conformadora da regra universal que a regra nos deixa órfãos para arbitrar sobre o certo e o errado.

Hauser refere-se a mundos morais possíveis e a seu fundamento na natureza. Fica sem resposta 
a questão: há, entre os mundos possíveis, um mundo melhor? Uma vez mais, a moral ultrapassa o discurso científico. 


\section{Notas}

${ }^{1}$ No entanto, Appiah não se refere ao importante livro de Marc Hauser aqui analisado.

${ }^{2}$ MALDONADO (2008) toma como objeto as mesmas teorias aqui tratadas e discute seu significado para o problema do livre-arbítrio- agradeço ao meu orientando Lincoln Frias a indicação do artigo.

${ }^{3}$ Não se trata, porém, de um consenso. Ver, por exemplo, DUPOUX e JACOB, 2008.

${ }^{4} \mathrm{O}$ exemplo, um "experimento mental", foi criado por Philippa Foot (1967) num artigo sobre o aborto no qual se discute o princípio do duplo efeito. Desenvolvido por Judith J. Thomsom, o trolley problem se encontra, com variações, em HAUSER, 2006, p.14 e em GREENE et allii, 2001.

${ }^{5}$ De fato, neste segundo texto ele está discutindo outro exemplo, o da pessoa atropelada versus o pedido de ajuda humanitária, mas a mesma interpretação se aplica.

${ }^{6}$ Respondendo a uma justa inquietação de Ricardo di Napoli, a quem agradeço os comentários ao meu texto, Hauser diria que nem todos os seres humanos possuem o senso moral. Alguns, como os psicopatas, etc, estariam privados dele justamente por disfunções cerebrais (no caso dos psicopatas, a disfunção ocorre na área das emoções). Podemos aqui lembrar a formulação de Hume: tanto a virtude quanto o vício são naturais. Assim, a moral se assenta no funcionamento íntegro do cérebro, embora o autor não afirme que ela se reduza a isso. (Ver Moral Minds, p. 235-237)

${ }^{7}$ Para uma avaliação crítica do projeto de uma Gramática Universal Moral ver DUPOUX e JACOB, 2008.

${ }^{8}$ Ao modo, imagino eu, do raciocínio humeano: não se observa empiricamente o "mal" nos atos, logo o "mal" não é objetivo (conhecido pela razão), mas subjetivo (matéria de sentimento ou emoção). Mas em Hume o que é subjetivo não é menos real que o que é objetivo, o que lhe permite fundar a moral nos afetos.

${ }^{9} \mathrm{O}$ que nos leva a outro ponto do problema: não há um consenso entre os cientistas sobre quais seriam estes princípios universais. Hauser identifica dois princípios que permitem distinguir entre o moral e o meramente convencional - os princípios de compaixão (evitar o mal) e de justiça. Já Haidt identifica seis princípios morais (compaixão, justiça, hierarquia, pureza, pertença ao grupo e elevação), mostrando que culturas diferentes acentuam princípios diferentes - o que torna o acordo multicultural mais complicado.

${ }^{10}$ RORTY, 2006.

${ }^{11}$ CLARKE, Steve. Review. Moral Minds. Minerva (2008). 46:147-48

${ }^{12}$ Este último raciocínio valeria também se estivesse em jogo a origem cultural dos valores. Sobre a falácia genética, ver JOYCE, 2001, 159-161.

${ }^{13}$ Para esta e outras críticas, ver RORTY, 2006. 


\section{Referências}

APPIAH, K. S. (2008) Experiments in Ethics. Cambridge (Mas.), Londres: Harvard University Press, 2008

CLARKE, S. Review. Moral Minds. Minerva (2008). 46:147-48

DUPOUX, E. e JACOB, P. (2008) Universal moral grammar: a critical appraisal. Trends in cognitive science. Vol 11, no. 9, 373-378.

FOOT, Philippa (1967). The problem of abortion and the doctrine of double effect. Oxford Review, 5, $5-15$.

GREENE, J. D., SOMMERVILLE, R. B. , NYSTROM, L. E. DARLEY, J. M. \& COHEN, J. D. (2001). An fMRI investigation of emotional engagement in moral judgement. In.: Science, 293, 2105-2108.

GREENE, J. D. (2003). From the neural "is" to the moral "ought": what are the moral implications of neuroscientific moral psychology? In.: Nature Neuroscience Reviews, 4, 847-850.

HAIDT, J. (2001). The emotional dog and its rational tail: A social intuitionist approach to moral judgements. In.: Psychological Review, 108, 814-834.

HAUSER, M. (2006). Moral Minds. How Nature designed our universal sense of right and wrong. Londres, Little, Brown.

JOYCE, R. (2001) The myth of morality. Cambridge University Press.

MALDONADO, M. (2008) Rumo a uma ciência do livre-arbítrio. Scientific American Brasil, Setembro 2008, 88-95.

PASCAL. B. (2001) Pensamentos. São Paulo, Editora Martins Fontes.

PENA, S. D. e BIRCHAL, T (2005-2006). A inexistência biológica versus a existência social das raças humanas: pode a ciência instruir o etos social? In.: Revista da USP, dezembro/janeiro/fevereiro 2005-2006. p. 10-21.

RORTY, R. (2006) Born to be good. The New York Times Books Review. August, 27, 2006.

WILSON, D. S., DIETRICH, E., CLARK, A. B. (2003) On the inappropriate use of naturalistic fallacy in evolutionary psychology. In.: Biology and Philosophy 18: 669-682. 